\title{
Photosynthetic pigments, betalains, proteins, sugars, and minerals during Salicornia brachiata senescence
}

\author{
A.K. PARIDA ${ }^{1,2 *}$, A. KUMARI ${ }^{1,2}$, A. PANDA ${ }^{1,2}$, J. RANGANI $^{1,2}$, and P.K. AGARWAL ${ }^{1,2}$ \\ Plant Omics Division, CSIR-CSMCRI, Bhavnagar-364002, Gujarat, India ${ }^{1}$ \\ Academy of Scientific and Innovative Research, CSIR-CSMCRI, Bhavnagar-364002, Gujarat, India ${ }^{2}$
}

\begin{abstract}
Senescence is the last developmental stage in plants during which recycling of nutrients takes place from senescing organs to newly formed organs such as young leaves and developing seeds. In the present work, senescence induced alterations in mineral ions, chlorophylls, carotenoids, betacyanin, betaxanthin, proteins, amino acids, sugars, starch, and polyphenols were monitored in shoots of an extreme halophyte Salicornia brachiata. A sharp decline in the content of chlorophylls, carotenoids, and proteins in the shoot was noticed at middle and late stages of senescence in comparison with early stage. However, the content of betacyanin, betaxanthin, total soluble sugars, reducing sugars, and starch increased significantly in senescing shoots. The total free amino acid content decreased gradually with the progress of senescence. The content of major minerals did not change significantly with the progress of senescence, whereas marked changes in content of minor minerals were observed. From this study, it was concluded that the sugars and starch accumulating in senescing shoots might be transported into developing seeds to serve as storage nutrients. The accumulation of betacyanin and betaxanthin in senescing shoots suggests that these pigments may act as scavengers of reactive oxygen species during senescence. This study provides comprehensive information on the variations in the utilization of mineral nutrients and organic metabolites with progressing senescence in the halophyte S. brachiata.
\end{abstract}

Additional key words: amino acid, betacyanin, betaxanthin, carotenoids, chlorophylls, halophyte, polyphenols, starch.

\section{Introduction}

Senescence is a coordinated physiological process in plants occurring in the final stage of the development of the whole plant, organ, tissue, or the cell that ultimately leads to the death. It is a vital process for recycling of nutrients from mature and senescing source leaves to newly-formed sink organs such as young leaves and developing seeds (Kim et al. 2007, Watanabe et al. 2013). Senescence that occurs as a part of normal development of the plants when growth conditions are near optimal is commonly referred to as developmental or age-dependent senescence, and it is induced and controlled by endogenous factors (Lers 2007). However, senescence may be induced prematurely via exposure to harsh environment. Key environmental stresses inducing premature senescence in plants are extreme temperatures, excess of radiation, drought, nutrient deficiency, presence of toxic materials, and pathogen infection (Lers 2007,
Obata and Fernie 2012).

Several phytohormones affect the processes during senescence. The cytokinin and ethylene have an extensive role in delaying or inducing leaf senescence, respectively (Sperotto et al. 2009, Davies and Gan 2012). Besides, other hormones, such as abscisic acid, auxins, gibberellic acid, jasmonic acid, and salicylic acid, also have a significant role in regulating the senescence processes (Schippers et al. 2007). The coordinated degradation of macromolecules and the remobilization of regained nutrients such as nitrogen, carbon, and minerals from senescing tissues into other parts of the plant are of vital importance (Zimmermann and Zentgraf 2005). The transport of metabolites from source leaves to sinks, such as developing seeds takes place through the vascular system and has a substantial role on crop yield and crop quality (Gregersen et al. 2013). Therefore, the vascular

Submitted 11 September 2015, last revision 26 may 2017, accepted 12 July 2017.

Abbreveations: ABTS - 2,2'-azino-bis-3-ethylbenzothiazoline-6-sulfonic acid; Car - carotenoid; Chl - chlorophyll; DPPH - 2,2-diphenyl-1-picrylhydrazyl; NBT - nitroblue tetrazolium; PMS - phenazine methoslphate; ROS reactive oxygen species; TCA - trichloroacetic acid.

Acknowledgments: This manuscript bears CSIR-CSMCRI Communication No. CSIR-CSMCRI 112/2014. Financial support from the Council of Scientific and Industrial Research (CSIR), New Delhi, India is gratefully acknowledged.

* Corresponding author; e-mail: asishparida@csmcri.org 
system is retained until the very late stages of senescence (Gan and Amasino 1997). It has been reported that the content of various minerals such as potassium, phosphorrous, iron, zinc, chromium, sulphur, molybdenum, carbon, copper, and zinc is reduced by more than $25 \%$ in senescent leaves of Arabidopsis thaliana as compared with the previous stages (Himelblau and Amasino 2001). This report suggests that mobilization of minerals takes place at the onset and during leaf senescence.

Leaf senescence is a highly regulated degenerative process involving a series of biochemical reactions (Buchanan-Wollaston et al. 2003, Lim and Nam 2005, Kim et al. 2007). The degradation of chlorophylls and breakdown of saccharides, lipids, proteins, and nucleic acids increase due to activation of hydrolytic enzymes during senescence, whereas the photosynthesis as well as protein synthesis decrease (Kim et al. 2007, Watanabe et al. 2013). Conversely, the fragmentation of DNA takes place at very late stage of senescence (Orzáez and Granell 1997, Zimmermann and Zentgraf 2005). The final stage of leaf senescence is a type of genetically controlled programmed cell death. During senescence, a massive change in gene expression occurs (Kim et al. 2007). The transcriptome analysis of senescing leaves showed that many genes are down-regulated but some genes are upregulated (Kim et al. 2007, Watanabe et al. 2013). In addition, various transcription factors are associated with leaf senescence (Lin and $\mathrm{Wu} 2004$ ).

Salicornia brachiata is a succulent and leafless annual. It is an obligate halophyte growing in the intertidal zones and salt marshes of Indian coast. It belongs to the family Chenopodiaceae. Whereas Mesembranthemum crystallinum shifts photosynthesis from the $\mathrm{C}_{3}$ mode to CAM to overcome high salinity,

\section{Materials and methods}

Plants: In January, the Salicornia brachiata Roxb. plants at different developmental stages categorized into mature plants (green), early senescence (greenish-yellow), and late senescence (red) were collected from a single community of salt marshes in Diu, Gujarat, India (latitude $20^{\circ} 44.5^{\prime} \mathrm{N}$ and longitude $70^{\circ} 56.0^{\prime} \mathrm{E}$ ). The shoot tissue was used for the measurement of various parameters and most of the methods mentioned below were described in detail previously (Parida and Jha 2004, 2013).

Estimation of ion content: The shoot samples $(0.5 \mathrm{~g})$ were dried in an oven at $70{ }^{\circ} \mathrm{C}$ for $48 \mathrm{~h}$, homogenized, and placed in a $100-\mathrm{cm}^{3}$ flask. The samples were digested by adding $10 \mathrm{~cm}^{3}$ of a mixture of $\mathrm{HNO}_{3}$ and $\mathrm{HClO}_{4}(9: 4)$ until the production of red $\mathrm{NO}_{2}$ fumes ceased. The content was further evaporated until the volume was reduced to $3-5 \mathrm{~cm}^{3}$. After cooling, the deionized water $\left(20 \mathrm{~cm}^{3}\right)$ was added and the solution was filtered through Whatman No. 1 filter paper. Aliquots of this solution were used for the determination of $\mathrm{Na}^{+}, \mathrm{K}^{+}, \mathrm{Ca}^{2+}, \mathrm{Mg}^{2+}$, $\mathrm{Mn}^{2+}, \mathrm{Zn}^{2+}, \mathrm{Cu}^{2+}$, and $\mathrm{Fe}^{2+}$ content by inductively coupled
Salicornia species are $\mathrm{C}_{3}$ plants. However, Salicornia species have the capability of efficient compartmentalization of toxic ions (Iyengar and Reddy 1997). In Salicornia, the spongy mesophyll cells are large and able to store a quantity of salts, whereas palisade tissue, where $80 \%$ of the photosynthetic pigments are located, remains relatively free of $\mathrm{Na}^{+}$and $\mathrm{Cl}^{-}$ions (Iyengar and Reddy 1997), and it is able to photosynthesize normally under high salinity (Iyengar and Reddy 1997). High ATPase activity is required to efflux toxic ions from palisade tissue to other non-photosynthetic tissues. Compartmentation of ions and high ATPase activity may be the adaptive features in Salicornia species to overcome high salinity (Iyengar and Reddy 1997). The developmental senescence of $S$. brachiata is visibly indicated by changes in shoot colour from green at an early stage to greenish yellow at middle stage and finally red at the terminal stage.

Senescence induced metabolic changes have been reported mostly in annual crops such as barley, maize, rice, wheat and some legumes (Crafts-Brandner et al. 1998; Yang et al. 2003; Robson et al. 2004; Parrott et al. 2005; Weng et al. 2005; Pick et al. 2011) and in model plant Arabidopsis (Diaz et al. 2005, Otegui et al. 2005, Watnabe et al. 2013). However, to the best of our knowledge, the changes in metabolites between presenescent and senescent tissues of the halophytes have not been investigated in detail so far. Therefore, in this work, a comprehensive study of senescence induced changes in the metabolites, including pigments, proteins, sugars, starch, amino acids, polyphenols, and mineral ions, have been carried out in the halophyte $S$. brachiata using shoots of three consecutive developmental stages.

plasma atomic absorption spectrometry (Optima 2000DV, Perkin Elmer, Waltham, MA, USA).

For estimation of nitrogen and phosphorous, the dried samples were digested with concentrated $\mathrm{H}_{2} \mathrm{SO}_{4}$ at $200{ }^{\circ} \mathrm{C}$ and decolorized using $\mathrm{H}_{2} \mathrm{O}_{2}(30 \%$, v/v). The total nitrogen content in shoot samples was determined following the colorimetric procedure and the absorbance was read at $650 \mathrm{~nm}$. The nitrogen content in the sample was determined from a standard curve prepared using $\left(\mathrm{NH}_{4}\right)_{2} \mathrm{SO}_{4}$ solution. The phosphorous content was estimated following the formation of a phosphomolybdate complex by adding $2.3 \mathrm{~cm}^{3}$ of a reagent made of 1 part of $10 \%(\mathrm{~m} / \mathrm{v})$ ascorbic acid and 6 parts of $0.42 \%(\mathrm{~m} / \mathrm{v})\left(\mathrm{NH}_{4}\right)_{6} \mathrm{MO}_{7} \mathrm{O}_{24} \cdot 4 \mathrm{H}_{2} \mathrm{O}$ in $0.5 \mathrm{M} \mathrm{H}_{2} \mathrm{SO}_{4}$. In order to complete formation of the complex, the solution was processed at $45{ }^{\circ} \mathrm{C}$ for $10 \mathrm{~min}$. The absorbance was measured at $820 \mathrm{~nm}$, and phosphorus content was read from a calibration curve prepared using analytical-grade $\mathrm{KH}_{2} \mathrm{PO}_{4}$.

Estimation of chlorophylls and carotenoids: About 
500-mg fresh shoot samples were homogenized with $80 \%$ acetone $(\mathrm{v} / \mathrm{v})$ in a pre-chilled pestle and mortar in the dark. The homogenates were centrifuged at $15000 \mathrm{~g}$ and $4^{\circ} \mathrm{C}$ for $10 \mathrm{~min}$ in a refrigerated centrifuge (Thermofisher Scientific, Waltham, USA). The absorption of the supernatant was read at 663.2, 646.8, and $470.0 \mathrm{~nm}$ in a microplate spectrophotometer using a quartz microtiter plate. Chlorophyll (Chl) $a, \mathrm{Chl} b$, total Chl, and carotenoids (Cars) were estimated following the method of Litchenthaler (1987).

Estimation of betalains: The betalains (betacyanin and betaxanthin) were extracted and purified following the procedure of Wang et al. (2006) with slight modifications. The shoot samples (approximately $5.0 \mathrm{~g}$ ) were homogenized in liquid nitrogen in a pre-chilled pestle and mortar. The homogenate was mixed with 10 volumes of methanol and centrifuged at $15000 \mathrm{~g}$ and $4{ }^{\circ} \mathrm{C}$ for $15 \mathrm{~min}$. The supernatant was discarded, and the pellet was re-extracted in 10 volumes of ethanol and was again centrifuged for $15 \mathrm{~min}$. This procedure was repeated once more to remove Chl, Cars, ascorbic acid, and tocopherol. To extract betalains, the pellet was then re-extracted with $50 \%$ ethanol for $30 \mathrm{~min}$ and centrifuged at the same conditions for $15 \mathrm{~min}$. The supernatant was mixed with a mixture of phenol, chloroform, and isoamyl alcohol $(25: 24: 1)$ and again centrifuged to remove proteins. The supernatant was re-extracted with a mixture of chloroform and isoamyl alcohol (24:1) to remove phenols. Then phenol phase was discarded, and the chloroform and isoamyl alcohol fraction was suspended with $50 \mathrm{mM}$ potassium phosphate buffer $(\mathrm{pH}$ 6.5), vortexed thoroughly and then centrifuged at $15000 \mathrm{~g}$ for $10 \mathrm{~min}$. The aqueous phase was collected, and the concentration of purified betacyanin and betaxanthin was estimated using the formula of Stintzing et al. (2003) after recording the absorbance of supernatant at 538 and $480 \mathrm{~nm}$.

Estimation of total protein content: Approximately $0.5 \mathrm{~g}$ of fresh shoot sample was homogenized with $5 \mathrm{~cm}^{3}$ of pre-chilled $10 \%(\mathrm{~m} / \mathrm{v})$ trichloroacetic acid (TCA) in $100 \%$ acetone solution containing $0.07 \% \beta$-mercaptoethanol in a chilled pestle and mortar. The homogenate was kept at $-20{ }^{\circ} \mathrm{C}$ for $2 \mathrm{~h}$ to precipitate the protein and then centrifuged at $10000 \mathrm{~g}$ and $4{ }^{\circ} \mathrm{C}$ for $15 \mathrm{~min}$. The supernatant was discarded, and the pellet was washed with $100 \%$ pre-chilled acetone and centrifuged under the same conditions to collect the protein pellet. The washing step was repeated three times. The supernatant was discarded, and the pellet was dissolved in $1 \mathrm{M} \mathrm{NaOH}$. The protein concentration was estimated by taking the absorption at $660 \mathrm{~nm}$ following the method of Lowry et al. (1951). Bovine serum albumin was used as a standard.

Estimation of content of total soluble sugars, reducing sugars, and starch: Approximately, $5.0 \mathrm{~g}$ of fresh shoots was extracted with $10 \mathrm{~cm}^{3}$ of $80 \%$ ethanol $(\mathrm{v} / \mathrm{v})$ in a pestle and mortar. The homogenate was incubated in water bath at $70{ }^{\circ} \mathrm{C}$ for $10 \mathrm{~min}$ and then centrifuged at $10000 \mathrm{~g}$ for $10 \mathrm{~min}$. The pellet was re-extracted twice with $80 \%$ ethanol, and the supernatants were pooled. An aliquot of this supernatant was evaporated to dryness in a rotary evaporator (R205, Buchi, Germany); the residue was re-dissolved in distilled water and utilized for the estimation of total soluble sugars, reducing sugars, and polyphenols. The pellet left after ethanolic extraction was solubilised with $52 \%$ perchloric acid and utilized for the estimation of starch.

Total soluble sugars and starch were estimated by anthrone-sulphuric acid using $0.2 \%(\mathrm{~m} / \mathrm{v})$ anthrone in concentrated $\mathrm{H}_{2} \mathrm{SO}_{4}$ as a reagent. Spectrophotometric readings were taken at $630 \mathrm{~nm}$. The standard curve was plotted with $0-100 \mu \mathrm{g}$ of glucose. Reducing sugars were estimated following alkaline copper method using arsenomolybdate reagent. Absorbance was recorded at $510 \mathrm{~nm}$ and reducing sugar content was determined from a standard curve prepared from pure glucose $(0-50 \mu \mathrm{g})$.

Estimation of total free amino acids: An aliquot of the ethanolic extract obtained above was evaporated to dryness in a rotary evaporator. The residue was re-dissolved in $0.2 \mathrm{M}$ citrate buffer ( $\mathrm{pH}$ 5.0). Total free amino acids were estimated using ninhydrin reagent. The absorbance was recorded at $570 \mathrm{~nm}$. The concentration of amino acid was calculated from a standard curve prepared using glycine $(0-100 \mu \mathrm{g})$.

Estimation of polyphenols: The polyphenol content was estimated from the ethanolic extract using FolinCiocalteau reagent. The absorbance was recorded at $650 \mathrm{~nm}$. A standard curve was prepared using several different concentrations of catechol $(0-100 \mu \mathrm{g})$.

Measurement of ROS scavenging activities: Fresh shoots $(5 \mathrm{~g})$ were grounded to a fine powder in liquid nitrogen and extracted in $50 \mathrm{~cm}^{3}$ of methanol $(80 \%, \mathrm{v} / \mathrm{v})$ by shaking at $100 \mathrm{rpm}$ for $24 \mathrm{~h}$ at room temperature. The extract was then freeze-dried in a lyophilizer and stored at $-20^{\circ} \mathrm{C}$ for further analysis.

DPPH radical scavenging activity of crude methanolic extract and purified betalain solution was determined using 2,2-diphenyl-1-picrylhydrazyl (DPPH) method (Prior et al. 2005). Freshly prepared DPPH methanol solution $(0.1 \mathrm{mM})$ was mixed with different aliquots $\left(20-100 \mathrm{~mm}^{3}\right)$ of crude methanolic extract or betalin solution and incubated for $30 \mathrm{~min}$ at room temperature in the dark. After incubation, the absorbance (A) was measured at $517 \mathrm{~nm}$. The scavenging activity was estimated using the following equation: scavenging $[\%]=$ $\left[\left(\mathrm{A}_{\text {control }}-\mathrm{A}_{\text {sample }}\right) / \mathrm{A}_{\text {control }}\right] \times 100$.

Total antioxidant activity of crude methanolic extract and purified betalain solution were measured by 2,2'-azino-bis-3-ethylbenzothiazoline-6-sulfonic acid (ABTS) decolorization assay according to the method of Re et al. (1999). In this assay, $\mathrm{ABTS}^{\circ+}$ was generated by reacting $7 \mathrm{mM}$ ABTS in $\mathrm{H}_{2} \mathrm{O}$ with $2.45 \mathrm{mM}$ potassium 
persulfate $\left(\mathrm{K}_{2} \mathrm{~S}_{2} \mathrm{O}_{8}\right)$ and incubating in the dark at room temperature for $16 \mathrm{~h}$. Prior to use, the $\mathrm{ABTS}^{\circ+}$ solution was diluted with $0.1 \mathrm{M}$ sodium phosphate buffer $(\mathrm{pH} 7.4)$ to give an absorbance of $0.750 \pm 0.025$ at $734 \mathrm{~nm}$. Then, $1 \mathrm{~cm}^{3}$ of ABTS $^{\circ+}$ solution was added to crude methanolic extract or betalain solution. The absorbance was recorded after $1 \mathrm{~min}$. The antioxidant capacity was calculated using the same equation as mentioned above.

The superoxide anion radical scavenging assay was done according to the method described by Saeed et al. (2012). Samples of crude methanolic extract or purified betalain solution were mixed with reaction mixture containing $0.5 \mathrm{~cm}^{3}$ of $50 \mathrm{mM}$ phosphate buffer ( $\mathrm{pH} 7.6$ ), $0.3 \mathrm{~cm}^{3}$ of $50 \mathrm{mM}$ riboflavin, $0.1 \mathrm{~cm}^{3}$ of $0.5 \mathrm{mM}$ nitroblue tetrazolium (NBT), and $0.25 \mathrm{~cm}^{3}$ of $20 \mathrm{mM}$ phenazine methosulphate (PMS). After $20 \mathrm{~min}$ of incubation under fluorescent lamp, the absorbance was measured at $560 \mathrm{~nm}$. The scavenging ability of the extract was determined by the same equation as mentioned above

Hydrogen peroxide scavenging activity was measured following the procedure of Saeed et al. (2012). Hydrogen peroxide solution $(2 \mathrm{mM})$ was prepared in $50 \mathrm{mM}$ potassium phosphate buffer ( $\mathrm{pH}$ 7.4). Aliquots of methanolic extract or betalain solution was transferred into the test tubes, and their volumes were made up to $0.4 \mathrm{~cm}^{3}$ with $50 \mathrm{mM}$ phosphate buffer $(\mathrm{pH} 7.4)$ After addition of $0.6 \mathrm{~cm}^{3}$ of hydrogen peroxide solution, tubes were vortexed and the absorbance of the hydrogen peroxide was determined after $10 \mathrm{~min}$ at $230 \mathrm{~nm}$, against a blank. Hydrogen peroxide scavenging activity was calculated using the same equation as mentioned above.

All the spectrophotometric analyses were performed in a UV-visible microplate spectrophotometer (Epoch $120821 B$, Biotek, Winooski, USA) using Gen5 v. 2.01.14 software (Biotek).

Statistical analyses: All the experiments were conducted with a minimum of three replicates, and the results were expressed as the mean \pm standard deviation (SD). All data were subjected to one-way analysis of variance (ANOVA) and Duncan's multiple-range test $(P \leq 0.05)$ using the Sigma Plot v. 12.0 (Systat Software, Chicago, IL, USA).

\section{Results}

Salicornia brachiata shows different phenotypic characteristics at various stages of development. The mature shoots are green, then the colour of shoots turns to greenish-yellow, and at the end of senescence the shoots are red (Fig. 1). In order to decipher the mechanisms involved in senescence of this species, various biochemical indicators were studied in shoots at different developmental stages. The $\mathrm{Na}^{+}$content decreased by $57 \%$ in greenish-yellow plants and increased by $7 \%$ in the red plants as compared to green plants. The $\mathrm{Ca}^{2+}$ content increased by $17 \%$ in greenish-yellow plants and decreased by $6 \%$ in red plants. The nitrogen content declined by 29 and $38 \%$, respectively, in greenish-yellow and red plants as compared to green plants. The $\mathrm{Fe}^{2+}$ content increased by $8 \%$ in greenish-yellow plants and decreased by $25 \%$ in red plants. In comparison to green plants, the $\mathrm{Zn}^{2+}$ content increased by 29 and $23 \%$, respectively, in greenish-yellow and red plants. The $\mathrm{Mn}^{2+}$ content increased by $18 \%$ in greenish-yellow plants, and a marginal increase of $9 \%$ was noticed in red plants. No significant change in the $\mathrm{Cu}^{2+}$ content was observed between green and greenish-yellow plants, however, about $29 \%$ decrease in $\mathrm{Cu}^{2+}$ content was observed in red plants in comparison to green plants. However, there were no significant changes in $\mathrm{K}^{+}, \mathrm{Mg}^{2+}, \mathrm{Ni}^{2+}$, and $\mathrm{P}$ content during plant development (Table 1).

The content of Chl $a$, Chl $b$, total Chl, and Cars decreased significantly with the progress of senescence (Table 2). It was observed that the $\mathrm{Chl} a$ content decreased by 61 and $85 \%$ in greenish-yellow and red plants, respectively, as compared to green plants, whereas the $\mathrm{Chl} b$ content decreased by $59.8 \%$ in greenish-yellow and by $80 \%$ in red plants. Similarly, the Cars content decreased by $27.5 \%$ in greenish-yellow plants and by 66 $\%$ in red plants in comparison to green plants. The Chl $a / b$ ratio decreased by $18 \%$ at greenish-yellow plants and by $33 \%$ in red plants (Table 2). Conversely, both betacyanin and betaxanthin content increased in S. brachiata shoots with the progress of senescence (Table 2). In comparison to green plants, the
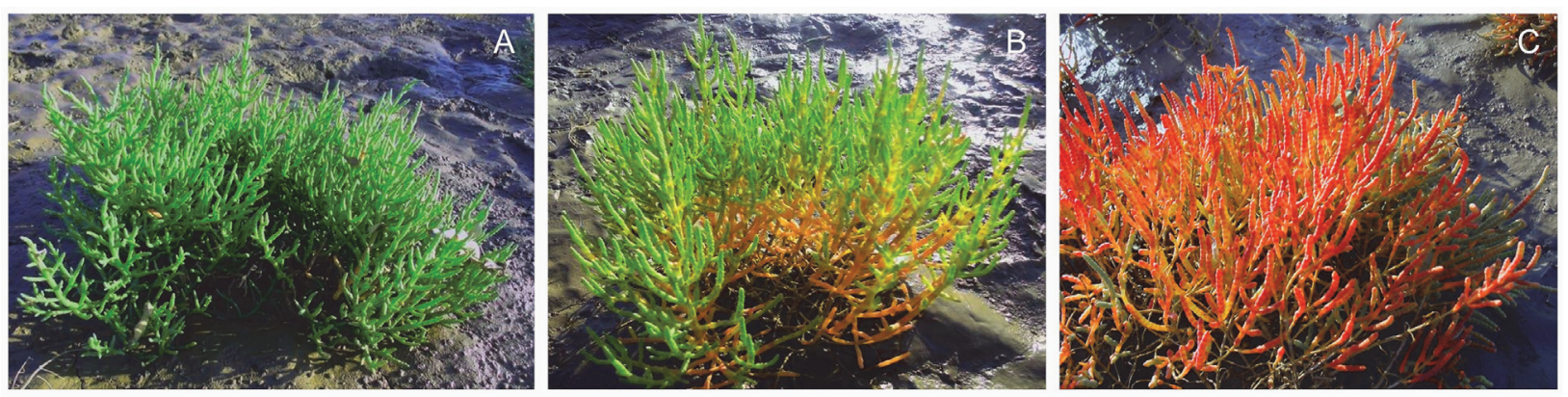

Fig. 1. Salicornia brachiata plants showing different phenotypic characteristics at different stages of development: $A$ - mature green plants, $B$ - greenish-yellow plants (early senescence), $C$ - senescent red plants. 
Table 1. Changes in the content of macro- and micro-nutrients in shoots of S. brachiata during different developmental stages. Means $\pm \mathrm{SDs}, n=4$. Means followed by different letters are significantly different at $P \leq 0.05$.

\begin{tabular}{|c|c|c|c|}
\hline Minerals & Green & Greenish-yellow & Red \\
\hline $\mathrm{Na}^{+}\left[\mathrm{mg} \mathrm{g}^{-1}\right.$ (d.m.) $]$ & $73.36 \pm 0.83 a$ & $31.53 \pm 7.62 b$ & $78.24 \pm 12.34 a c$ \\
\hline $\mathrm{K}^{+}\left[\mathrm{mg} \mathrm{g}^{-1}\right.$ (d.m.) $]$ & $12.31 \pm 1.61 \mathrm{a}$ & $14.73 \pm 3.76 \mathrm{a}$ & $13.65 \pm 2.34 \mathrm{a}$ \\
\hline $\mathrm{Ca}^{2+}\left[\mathrm{mg} \mathrm{g}^{-1}\right.$ (d.m.) $]$ & $2.71 \pm 0.26 \mathrm{a}$ & $3.17 \pm 0.69 b$ & $2.54 \pm 0.14 \mathrm{ac}$ \\
\hline $\mathrm{Mg}^{2+}\left[\mathrm{mg} \mathrm{g}^{-1}\right.$ (d.m.) $]$ & $3.68 \pm 0.13 \mathrm{a}$ & $3.72 \pm 0.35 \mathrm{a}$ & $3.82 \pm 0.15 \mathrm{a}$ \\
\hline $\mathrm{N}\left[\mathrm{mg} \mathrm{g}^{-1}\right.$ (d.m.) $]$ & $4.24 \pm 0.74 b$ & $3.01 \pm 0.47 \mathrm{a}$ & $2.61 \pm 0.30 \mathrm{a}$ \\
\hline $\mathrm{P}\left[\mathrm{mg} \mathrm{g}^{-1}\right.$ (d.m.) $]$ & $0.21 \pm 0.07 \mathrm{a}$ & $0.27 \pm 0.05 a$ & $0.23 \pm 0.05 a$ \\
\hline $\mathrm{Fe}^{2+}\left[\mu \mathrm{g} \mathrm{g}^{-1}\right.$ (d.m.) $]$ & $458.08 \pm 34.8 \mathrm{a}$ & $495.08 \pm 56.3 \mathrm{ab}$ & $345.96 \pm 40.7 \mathrm{c}$ \\
\hline $\mathrm{Zn}^{2+}\left[\mu \mathrm{g} \mathrm{g}^{-1}\right.$ (d.m.) $]$ & $37.93 \pm 5.71 \mathrm{a}$ & $48.97 \pm 9.78 b$ & $46.53 \pm 6.89 b c$ \\
\hline $\mathrm{Mn}^{2+}\left[\mu \mathrm{g} \mathrm{g}^{-1}\right.$ (d.m.) $]$ & $27.09 \pm 2.12 \mathrm{a}$ & $31.91 \pm 8.05 b$ & $29.63 \pm 1.90 \mathrm{ac}$ \\
\hline $\mathrm{Cu}^{2+}\left[\mu \mathrm{g} \mathrm{g}^{-1}\right.$ (d.m.)] & $5.02 \pm 0.72 \mathrm{a}$ & $4.81 \pm 0.79 a$ & $3.56 \pm 0.13 b$ \\
\hline $\mathrm{Ni}^{2+}\left[\mu \mathrm{g} \mathrm{g}^{-1}\right.$ (d.m.) $]$ & $3.16 \pm 0.21 \mathrm{a}$ & $3.19 \pm 0.44 \mathrm{a}$ & $3.42 \pm 0.54 \mathrm{a}$ \\
\hline
\end{tabular}

Table 2. Changes in the content of various pigments in shoots of $S$. brachiata during different developmental stages. Means \pm SDs, $n=4$. Means followed by different letters are significantly different at $P \leq 0.05$.

\begin{tabular}{|c|c|c|c|}
\hline Pigments & Green & Greenish-yellow & Red \\
\hline Chl $a\left[\mu \mathrm{g} \mathrm{g}^{-1}\right.$ (d.m.) $]$ & $574.6 \pm 68.8 \mathrm{a}$ & $221.9 \pm 57.3 b$ & $84.3 \pm 21.9 c$ \\
\hline Chl $b\left[\mu \mathrm{g} \mathrm{g}^{-1}\right.$ (d.m.) $]$ & $170.6 \pm 21.4 \mathrm{a}$ & $68.5 \pm 15.8 b$ & $35.0 \pm 10.8 \mathrm{c}$ \\
\hline $\mathrm{Chl} a / b$ & $3.3 \pm 0.1 \mathrm{a}$ & $2.7 \pm 0.6 b$ & $2.2 \pm 0.4 b$ \\
\hline Total Chl $\left[\mu g g^{-1}(\right.$ d.m. $\left.)\right]$ & $746.5 \pm 88.9 a$ & $307.0 \pm 80.6 b$ & $119.5 \pm 32.6 \mathrm{c}$ \\
\hline Cars $\left[\mu \mathrm{g} \mathrm{g}^{-1}\right.$ (d.m.) $]$ & $433.8 \pm 46.0 \mathrm{a}$ & $314.2 \pm 72.0 \mathrm{~b}$ & $147.5 \pm 53.8 \mathrm{c}$ \\
\hline Betacyanin $\left[\mu \mathrm{g} \mathrm{g}^{-1}\right.$ (d.m.)] & $8.9 \pm 1.1 \mathrm{a}$ & $30.0 \pm 5.5 b$ & $32.5 \pm 2.9 b$ \\
\hline Betaxanthin $\left[\mu \mathrm{g} \mathrm{g}^{-1}\right.$ (d.m.) $]$ & $28.7 \pm 5.3 \mathrm{a}$ & $49.0 \pm 6.9 b$ & $62.3 \pm 8.7 \mathrm{c}$ \\
\hline
\end{tabular}

betacyanin content increased by 237 and $265 \%$, respectively, in greenish-yellow and red plants and the betaxanthin content increased by 70 and $117 \%$, respectively, in greenish-yellow and red plants (Table 2).

It was observed that content of total free amino acids and proteins in shoot decreased gradually with the progress of senescence. As compared to green plants, the content of free amino acids decreased by $56 \%$ in greenish-yellow plants and by $72 \%$ in red plants (Table $3)$. The total protein content decreased by $26 \%$ in greenish-yellow plants and by $31 \%$ in red plants as compared to green plants (Table 3 ). On the contrary, the total soluble sugarr, reducing sugars, and starch content increased significantly during development. As compared to green plants, the total soluble sugars content increased by 170 and $55 \%$ in greenish-yellow and red plants, respectively. The reducing sugars content increased by 95 and $140 \%$, respectively, in greenish-yellow and red plants as compared to green plants. The starch content increased by $64-68 \%$ in greenish-yellow and red plants as compared to green plants (Table 3). The total polyphenol content decreased by $31 \%$ in greenish-yellow plants and by $8 \%$ in red plants as compared to green plants (Table 3 ).

The ROS scavenging activities of $S$. brachiata shoot were measured as DPPH radical scavenging, ABTS radical cation decolorization, and $\mathrm{O}_{2}{ }^{-}$and $\mathrm{H}_{2} \mathrm{O}_{2}$ scavenging assays. The crude extracts and purified

Table 3. The content of various organic compounds $\left[\mathrm{mg} \mathrm{g}^{-1}\right.$ (d.m.)] in shoots of $S$. brachiata during different developmental stages. Means \pm SDs, $n=4$. Different letters indicate statistically different means at $P \leq 0.05$.

\begin{tabular}{lrrr}
\hline Organic metabolites & Green & Greenish-yellow & Red \\
\hline Total soluble sugars & $39.9 \pm 4.1 \mathrm{a}$ & $107.9 \pm 14.0 \mathrm{~b}$ & $100.3 \pm 15.1 \mathrm{~b}$ \\
Reducing sugars & $10.6 \pm 2.1 \mathrm{a}$ & $20.7 \pm 1.6 \mathrm{~b}$ & $25.6 \pm 2.8 \mathrm{c}$ \\
Starch & $28.2 \pm 4.6 \mathrm{a}$ & $47.3 \pm 12.1 \mathrm{~b}$ & $46.5 \pm 11.7 \mathrm{~b}$ \\
Proteins & $38.0 \pm 5.6 \mathrm{a}$ & $28.1 \pm 1.7 \mathrm{~b}$ & $26.2 \pm 4.2 \mathrm{~b}$ \\
Amino acids & $2.4 \pm 0.3 \mathrm{a}$ & $1.4 \pm 0.2 \mathrm{~b}$ & $1.0 \pm 0.05 \mathrm{c}$ \\
Polyphenols & $3.9 \pm 0.1 \mathrm{a}$ & $3.0 \pm 0.1 \mathrm{~b}$ & $3.7 \pm 0.2 \mathrm{a}$ \\
\hline
\end{tabular}


betalain solutions from green, greenish-yellow, and red shoots were used (Fig. 2). The overall antioxidant and ROS scavenging activities of crude methanolic extracts were the highest in the greenish-yellow shoots, moderate in the red shoots, and the lowest in the green shoots

\section{Discussion}

Senescence is a synchronized process during which a plant or a part of the plant retrieve nutrients and remobilize them to younger tissues or to developing seeds (Ricachenevsky et al. 2013). In the present work, development associated changes in mineral nutrients and metabolites such as pigments, protein, amino acids, sugars, and polyphenols were studied using samples collected from an extreme halophyte $S$. brachiata at different developmental stages with the aim to ascertain the mechanism of nutrient recycling and metabolic shift during senescence. Some of mineral elements are

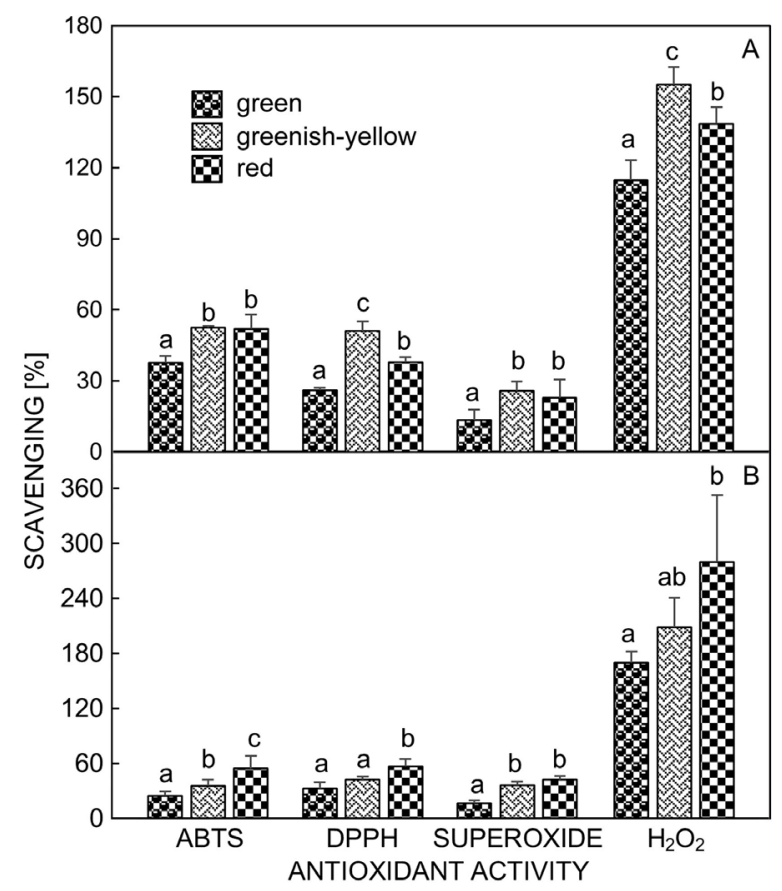

Fig. 2. Antioxidant properties of $S$. brachiata measured in terms of DPPH radical, ABTS radical, $\mathrm{O}_{2}{ }^{--}$radical, and $\mathrm{H}_{2} \mathrm{O}_{2}$ scavenging activities in shoots of different developmental stages. $A$ - Crude methanolic extracts $\left(200 \mu \mathrm{g} \mathrm{mm}^{-3}\right)$; $B$ - betalain solutions $\left(100 \mu \mathrm{g} \mathrm{cm} \mathrm{cm}^{-3}\right)$. Means \pm SDs, $n=4$. Different letters indicate statistically different means at $P \leq 0.05$.

required in large quantities (macronutrients $\mathrm{N}, \mathrm{P}, \mathrm{S}, \mathrm{K}$, $\mathrm{Ca}$, and $\mathrm{Mg}$ ) and some in small quantities (micronutrients Fe, Mn, Zn, Cu, B, Mo, Cl, and Ni) (Fischer 2007). Rather high accumulation of $\mathrm{Na}^{+}$is a typical feature of the halophytic plants (Zhu 2003). Most of the halophytes compartmentalize $\mathrm{Na}^{+}$ions into vacuoles to mitigate the toxic effects of $\mathrm{Na}^{+}$. In addition, $\mathrm{Na}^{+}$accumulation in the
(Fig. 2A). However, when betalain solutions were used, all the ROS scavenging activities increased in red shoots as compared to green and greenish-yellow shoots (Fig. 2B).

succulent stems is one of the strategies of succulent halophytes (Rabhi et al. 2010). It has been reported that plants grown under high salinity usually absorb more $\mathrm{Na}^{+}$ and less $\mathrm{K}^{+}$than control plants (Shi and Wang 2005, Yang et al. 2007). S. brachiata is an extreme halophytic species and grows in salt marshes. The high absorption of $\mathrm{Na}^{+}$in $S$. brachiata growing under extreme salinity inhibits the $\mathrm{K}^{+}$absorption due to competitive inhibition between $\mathrm{Na}^{+}$and $\mathrm{K}^{+}$. Moreover, high saline conditions can break the ion balance and disturb the $\mathrm{K}^{+}$and $\mathrm{Ca}^{2+}$ distribution in the cell (Yang et al. 2007). The plants need to establish the ion balance in the cell under salinity for the tolerance and survival. In $S$. brachiata $\mathrm{Na}^{+}$is considered as the main inorganic osmolyte under saline conditions, but in the absence of $\mathrm{NaCl}, \mathrm{K}^{+}$mainly acts as the inorganic osmolyte (Yang et al. 2007). Higher $\mathrm{Na}^{+}$ content as compared to $\mathrm{K}^{+}$content has also been reported in the Aneurolepidium chinense (Shi and Wang 2005), Kochia sieversiana (Yang et al. 2007), and many other halophytes. The mineral nutrients from senescing plant parts are re-translocated to the seeds or other surviving structures such as bulbs and roots (Fischer 2007). In $S$. brachiata, the marginal changes in $\mathrm{Na}^{+}$and $\mathrm{Ca}^{2+}$ content of the shoot were observed at a late stage of senescence, and there were no significant changes in $\mathrm{K}^{+}$ and $\mathrm{Mg}^{2+}$ content. In contrast to our results, it has been reported that $\mathrm{K}^{+}$easily leaches from senescing tissues of wheat or Fagus (Debrunner and Feller 1995, Tyler 2005). The $\mathrm{N}$ content of shoot declined gradually with the progress of senescence together with amino acid and protein content. The decline of protein content may be attributed to the increased proteolysis (Hortensteiner and Feller 2002). On the contrary, there was no significant difference in the phosphorous content of green, greenishyellow and red shoots. The $\mathrm{Zn}^{2+}$ and $\mathrm{Mn}^{2+}$ content of shoot increased significantly at the late stage of senescence, whereas a marked decrease in $\mathrm{Fe}^{2+}$ and $\mathrm{Cu}^{2+}$ content was observed in $S$. brachiata with the progress of senescence. Our results suggest that important macronutrients are maintained whereas content of micronutrients changes during the senescence.

In $S$. brachiata, a significant loss of $\mathrm{Chl}$ and Car content was observed with the progress of senescence. Our results are in agreement with Lee et al. (2003), who have reported that both $\mathrm{Chl}$ and Car are broken down during senescence. However, usually more of the Car are retained than $\mathrm{Chl}$ resulting in yellow coloration of leaves during senescence (Hörtensteiner and Lee 2007). It has been reported that $\mathrm{Chl}$ breakdown is an important 
catabolic process during fruit ripening (Hörtensteiner and Kräutler 2011). Lim et al. (2007) reported that loss of green colour visually marks the initiation of metabolic changes that occur during senescence. In addition, senescence is accompanied by decline in photosynthesis and the massive degradation of cellular proteins (Sakuraba et al. 2012). It has been reported that the Chl degradation produces various colourless catabolites known as non-fluorescent chlorophyll catabolites (NCCs) (Kraütler 2008, Hörtensteiner 2009, Hörtensteiner and Kraütler 2011, Sakuraba et al. 2012). NCCs are the low molecular mass tetrapyrrolic compounds having effective antioxidant properties (Kraütler 2008). These NCCs are photodynamically safe, because they do not absorb visible radiation thereby protecting the plants from photooxidative damage during senescence (Hörtensteiner and Kraütler 2011). In S. brachiata, it was observed that the chlorophyll degradation in senescing shoots was positively correlated with the ROS scavenging activities. The above evidences suggest that the chlorophyll degradation in S. brachiata might have some role in ROS detoxification during senescence. The declining Chl $a / b$ ratio at a late stage of senescence suggests that the lightharvesting complexes of thylakoid membranes are affected by senescence in S. brachiata (Parida and Jha 2013).

It has been reported that betacyanins together with betaxanthins belong to a class of nitrogenous chromoalkaloids known as betalains. Although anthocyanins are widely distributed in higher plants, betacyanins accumulate only in ten families of the order Caryophyllales (e.g., Amaranthaceae, Cactaceae, and Chenopodiaceae). In these species, betacyanins replace anthocyanins, and these pigments are not found simultaneously in the same plant (Stafford 1994). Salicornia brachiata belongs to the family Chenopodiaceae, and red pigmentation of its shoots is due to the presence of betacyanin (Davy et al. 2001). A considerable increase in betacyanin and betaxanthin content was observed in the shoot of $S$. brachiata with the progress of senescence. Wang et al. (2006) have reported that betacyanin synthesis is induced by low temperature and high salinity in the halophyte Suaeda salsa. In Suaeda japonica, the betacyanin accumulation increases under significant drop in temperature (Hayakawa and Agarie 2010). Vogt et al. (1999) reported that betacyanin synthesis is induced by UV-A in Mesembryanthemum crystallinum. It has been reported that betalains act as ROS scavengers (Hayakawa and Agarie 2010). In S. brachiata, ROS scavenging activities were positively correlated with betalain accumulation in shoots. Our results showed that betalains (betacyanin and betaxanthin) production increased with the progress of senescence and it was important for scavenging potentially cytotoxic ROS. Both water-soluble pigments anthocyanins and betalains accumulate in the vacuoles (Tanaka et al. 2008). $\mathrm{H}_{2} \mathrm{O}_{2}$ rapidly accumulates in the chloroplast stroma during photoinhibition and further diffuses to other cell compartments (Nakano and Asada
1981). The juvenile and senescing leaves seem to have increased need of photoprotection. Therefore, an anthocyanin or betalain-rich vacuole acts as a potential sink for excess $\mathrm{H}_{2} \mathrm{O}_{2}$ produced in the chloroplast, alleviating the photo-oxidative damage to the plants (Kytridis and Manetas 2006). In addition to protection from photo-oxidative damage, the anthocyanins or betalains may act as the osmolytes (Hughes 2011). In S. brachiata, enhanced biosynthesis of betacyanin and betaxanthin with the progress of senescence may take part in both ROS scavenging and osmotic adjustment.

A gradual decrease in total free amino acid content was observed in S. brachiata with the progress of senescence. In a similar pattern, a decrease in free amino acid content has also been reported in tobacco and oat leaves (Masclaux et al. 2000, Soudry et al. 2005). The decrease in the content of amino acids may be due to membrane leakage during senescence (Soudry et al. 2005). However, in Arabidopsis, both the attached and detached leaves exhibit a gradual increase in amino acid content during senescence (Soudry et al. 2005). These results suggest that total free amino acid pools do not have a universal regulatory role in triggering senescence (Masclaux et al. 2000, Soudry et al. 2005). It has been reported that senescence-related proteases play significant roles in leaf senescence by regulating protein degradation and nutrient recycling (Wang et al. 2013, Wu et al. 2016). In S. brachiata the total protein content gradually decreased with the progression of senescence. The decline in the protein content may be due to the proteolysis associated with onset of senescence. In most plant tissues, the proteins contain the largest fraction of organic nitrogen, which is potentially available for remobilization during senescence (Fischer 2007, Wu et al. 2016). The decrease in the content of total protein may be the reason for the decline in the nitrogen content of the senescing shoots of S. brachiata.

Like other cellular constituents, sugars, starch, and polyphenols are also affected by senescence in $S$. brachiata. A significant increase in total sugars, reducing sugars, and starch content was observed in S. brachiata with the progress of senescence. Conversely, all individual sugars and starch content decrease with increasing age of Lactuca sativa (Witkowska and Woltering 2013). In agreement with our results, Masclaux et al. (2000) have reported an increase in sugar content with a concomitant decline in photosynthesis in tobacco leaves during senescence. It has been reported that cytokinin production increases during senescence in lettuce resulting an abnormally high accumulation of sugars in upper leaves that lead to premature senescence (McCabe et al. 2001). It has been proposed that the accumulation of sugars in mature leaves leads to a decline of photosynthetic activity and a certain threshold content of sugars may act as a senescence signal (Kim et al. 2007). The increase in sugar content with the progression of senescence has been reported in many plant species. It has been reported that increase in the sugar content with a concomitant decline in nitrogen content in leaves play a 
role in the induction of leaf senescence (Hortensteiner and Feller 2002), which is in accordance with our results. The expression of senescence-associated gene SAG12, which is highly senescence specific, is induced severalfold by growth on glucose in combination with low nitrogen (Pourtau et al. 2004, Wingler et al. 2006). $S A G 12$ is expressed late during the senescence process, and it has been argued that late $S A G s$ are sugarrepressible, whereas early SAGs are sugar-inducible (Paul and Pellny 2003, Wingler et al. 2006). Thus, some soluble sugars probably act as important regulatory molecules for triggering senescence (Dai et al. 1999, Xiao et al. 2000, Soudry et al. 2005). Generally, a decline in starch content of leaf with a concomitant increase in sugar content is common in many plant species subjected to abiotic stresses (Parida and Jha 2013). However, in $S$. brachiata concomitant increase in total soluble sugars and starch content was observed during senescence. The increase in starch content may be due to the synthesis of starch from sugars. Sugars may be extensively available for starch synthesis because they may not be consumed in plant growth during the senescence.

The polyphenols are considered as powerful nonenzymatic ROS scavengers in plants (Yildiz-Aktas et al. 2009, Parida and Jha 2013) and they help the plants to adapt to harsh environmental conditions. There are several reports of the role of polyphenols in energy dissipation and ROS scavenging (Edreva 2005, YildizAktas et al. 2009, Parida and Jha 2013), and the synthesis of these metabolites is stimulated in plants under salt stress (Reginato et al. 2014). Apart from defence against ROS, the polyphenols (predominantly flavonoids) also have other roles such as UV screening and developmental regulators (Ferdinando et al. 2014). In S. brachiata, a marginal increase in polyphenol content was observed at the late stage of senescence. It has been reported that the polyphenol content in leaves does not differ between maturity stages of Lactuca sativa (Witkowska and Woltering 2013). The contrasting results between $S$. brachiata and L. sativa suggest that the polyphenols do not have a universal regulatory role in triggering senescence.

In conclusion, the data presented in this work reveal that the content of important major mineral nutrients was preserved in $S$. brachiata, whereas the content of minor nutrients varied with the progress of senescence. The enhanced biosynthesis of both betacyanin and betaxanthin with progress of senescence took place in ROS scavenging and osmotic adjustment. In $S$. brachiata total free amino acids pools did not have a regulatory role in triggering senescence. The decline in the protein content in S. brachiata with progress of senescence may be due to the proteolysis associated with onset of senescence and may be the reason for the decline in the nitrogen content in the senescing shoots. The soluble sugars serve as important regulators for triggering senescence in this plant.

\section{References}

Buchanan-Wollaston, V.: The molecular biology of leaf senescence. - J. exp. Bot. 48: 181-199, 1997.

Buchanan-Wollaston, V., Earl, S., Harrison, E., Mathas, E., Navabpour, S., Page, T., Pink, D.: The molecular analysis of leaf senescence - a genomics approach. - Plant. Biotechnol. J. 1: 3-22, 2003.

Crafts-Brandner, S.J., Hölzer, R., Feller, U.: Influence of nitrogen deficiency on senescence and the amounts of RNA and proteins in wheat leaves. - Physiol. Plant. 102: 192-200, 1998.

Dai, N., Schaffer, A., Petreikov, M., Shahak, Y., Giller, Y., Ratner, K., Levine, A., Granot, D.: Overexpression of Arabidopsis hexokinase in tomato plants inhibits growth, reduces photosynthesis, and induces rapid senescence. Plant Cell 11: 1253-1266, 1999.

Davies, P.J., Gan, S.: Towards an integrated view of monocarpic plant senescence. - Russ. J. Plant Physiol. 59: 467-478, 2012.

Davy, A.J., Bishop, G.F., Costa, C.S.B.: Salicornia L. (Salicornia pusilla J. Woods, S. ramosissima J. Woods, $S$. europaea L., S. obscura P.W. Ball \& Tutin, S. nitens P.W. Ball \& Tutin, S. fragilis P.W. Ball \& Tutin and $S$. dolichostachya Moss). - J. Ecol. 89: 681-707, 2001.

Debrunner, N., Feller, U.: Solute leakage from detached plant parts of winter wheat: influence of maturation stage and incubation temperature. - J. Plant. Physiol. 145: 257-260, 1995.

Diaz, C., Purdy, S., Christ, A., Morot-Gaudry, J.F., Wingler. A, Masclaux-Daubresse, C.: Characterization of markers to

determine the extent and variability of leaf senescence in Arabidopsis. A metabolic profiling approach. - Plant Physiol. 138: 898-908, 2005.

Edreva, A.: The importance of non-photosynthetic pigments and cinnamic acid derivatives in photoprotection. - Agr. Ecosyst. Environ. 106: 135-146, 2005.

Ferdinandoa, M.D., Brunettia, C., Agatib, G., Tattinic, M.: Multiple functions of polyphenols in plants inhabiting unfavorable Mediterranean areas. - Environ. exp. Bot. 103: 107-116, 2014.

Fischer, A.M.: Nutrient remobilization during leaf senescence. In: Gan, S. (ed): Annual Reviews of Senescence Processes in Plants. Vol. 26. Pp. 87-107. Blackwell Publishing, Oxford 2007.

Gan, S., Amasino, R.M.: Making sense of senescence; molecular genetic regulation and manipulation of leaf senescence. - Plant. Physiol. 113: 313-319, 1997.

Gregersen, P.L., Culetic, A., Boschian, L., Krupinska, K.: Plant senescence and crop productivity. - Plant mol. Biol. 82: 603-622, 2013.

Hayakawa, K., Agarie, S.: Physiological roles of betacyanin in a halophyte, Suaeda japonica Makino. - Plant Prod. Sci. 13: 351-359, 2010.

Himelblau, E., Amasino, R.M.: Nutrients mobilized from leaves of Arabidopsis thaliana during leaf senescence. - J. Plant. Physiol. 158: 1317-1323, 2001.

Hörtensteiner, S.: Stay-green regulates chlorophyll and chlorophyll-binding protein degradation during senescence. - Trends Plant Sci. 14: 155-162, 2009. 
Hörtensteiner, S., Feller, U.: Nitrogen metabolism and remobilization during senescence. - J. exp. Bot. 53: 927 937, 2002.

Hörtensteiner, S., Kräutler, B.: Chlorophyll breakdown in higher plants. - Biochim. biophys. Acta 1807: 977-988, 2011.

Hörtensteiner, S., Lee, D.W.: Chlorophyll catabolism and leaf coloration. - In: Gan, S. (ed.): Annual Reviews of Senescence Processes in Plants. Vol. 26. Pp. 12-38. Blackwell Publishing, Oxford 2007.

Hughes, M.M.: Winter leaf reddening in 'evergreen' species. New Phytol. 190: 573-581, 2011.

Iyengar, E.R.R., Reddy, M.P.: Photosynthesis in highly salt tolerant plants. - In: Pesserakali, M. (ed.): Handbook of Photosynthesis. Pp. 897-909. Marcel Dekker, New York 1997.

Kim, H.J., Lim, P.O., Nam, H.G.: Molecular regulation of leaf senescence. - In: Gan, S. (ed.): Annual Review of Senescence Processes in Plants. Vol. 26. Pp. 231-255. Blackwell Publishing, Oxford 2007.

Kytridis, V.P., Manetas, Y.: Mesophyll versus epidermal anthocyanins as potential in vivo antioxidants: evidence linking the putative antioxidant role to the proximity of oxyradical source. - J. exp. Bot. 57: 2203-2210, 2006.

Kraütler, B.: Chlorophyll breakdown and chlorophyll catabolites in leaves and fruit. - Photochem. Photobiol. 7: 1114-1120, 2008.

Lee, D.W., O'Keefe, J., Holbrook, N.M., Feild, T.S.: Pigment dynamics and autumn leaf senescence in a New England deciduous forest, eastern USA. - Ecol. Res. 18: 677-694, 2003.

Lers, A.: Environmental regulation of leaf senescence. - In: Gan, S. (ed.): Annual Review of Senescence Processes in Plants. Vol. 26. Pp. 231-255. Blackwell Publishing, Oxford 2007.

Lim, P.O., Kim, H.J., Nam, H.G.: Leaf senescence. - Annu. Rev. Plant. Biol. 58: 115-136, 2007.

Lim, P.O., Nam, H.G.: The molecular and genetic control of leaf senescence and longevity in Arabidopsis. - Curr. Topics dev. Biol. 67: 49-83, 2005.

Lin, J.F., Wu, S.H.: Molecular events in senescing Arabidopsis leaves. - Plant. J. 39: 612-628, 2004.

Litchenthaler, H.K.: Chlorophylls and carotenoids pigments of photosynthetic biomembranes. - Method. Enzymol. 148: 350-383, 1987

Lowry, O.H., Rosebrough, N.J., Farr, L.A., Randall, R.J.: Protein measurement with the Folin phenol reagent. - Anal. Biochem. 193: 265-275, 1951.

Masclaux, C., Valadier, M.H., Brugiere, N., Morot-Gaudry, J.F., Hirel, B.: Characterization of the sink/source transition in tobacco (Nicotiana tabacum L.) shoots in relation to nitrogen management and leaf senescence. - Planta 211: 510-518, 2000

McCabe, M.S., Garratt, L.C., Schepers, F., Jordi, W.J.R.M., Stoopen,G.M., Davelaar, E., Hans, J., Rhijn V.A., Power B.J., Davey M.R.: Effects of PSAG12-IPT gene expression on development and senescence in transgenic lettuce. - Plant Physiol. 127: 505-516, 2001.

Nakano, Y., Asada, K.: Spinach chloroplasts scavenge hydrogen peroxide on illumination. - Plant Cell. Physiol. 21: 12951307, 1981.

Obata, T., Fernie, A.R.: The use of metabolomics to dissect plant responses to abiotic stresses. - Cell. mol. Life Sci. 69: 3225-3243, 2012

Orzáez, D., Granell, A.: DNA fragmentation is regulated by ethylene during carpel senescence in Pisum sativum. - Plant. J. 11: 137-144, 1997.

Otegui, M.S., Noh, Y.S., Martínez, D.E., Vila Petroff, M.G., Staehelin, L.A., Amasino, R.M., Guiamet, J.J.: Senescenceassociated vacuoles with intense proteolytic activity develop in leaves of Arabidopsis and soybean. - Plant J. 41: 831844, 2005.

Parida, A.K., Das, A.B.: Effects of $\mathrm{NaCl}$ stress on nitrogen and phosphorous metabolism in a true mangrove Bruguiera parviflora grown under hydroponic culture. - J. Plant Physiol. 161: 921-928, 2004.

Parida, A.K., Jha, B.: Physiological and biochemical responses reveal the drought tolerance efficacy of the halophyte Salicornia brachiata. - J. Plant Growth Regul. 32: 342-352, 2013.

Parrott, D., Yang, L., Shama, L., Fischer, A.M.: Senescence is accelerated, and several proteases are induced by carbon 'feast' conditions in barley (Hordeum vulgare L.) leaves. Planta 222: 989-1000, 2005.

Paul, M.J., Pellny, T.K.: Carbon metabolite feedback regulation of leaf photosynthesis and development. - J. exp. Bot. 54: 539-547, 2003.

Pick, T.R., Bräutigam. A., Schlüter. U., Denton, A.K., Colmsee, C., Scholz, U., Fahnenstich, H., Pieruschka, R., Rascher, U., Sonnewald, U., Weber, A.P.M.: Systems analysis of a maize leaf developmental gradient redefines the current $\mathrm{C} 4$ model and provides candidates for regulation. - Plant Cell 23: 4208-4220, 2011

Pourtau, N., Marés, M., Purdy, S., Quentin, N., Ruël, A., Wingler, A.: Interactions of abscisic acid and sugar signalling in the regulation of leaf senescence. - Planta 219: 765-772, 2004.

Prior, R.L., Wu, X., Schaich, K.: Standardized methods for the determination of antioxidant capacity and phenolics in foods and dietary supplements. - J. Agr. Food Chem. 53: 4290$4302,2005$.

Rabhi, M., Ferchichi, S., Jouini, J., Hamrouni, M.H., Koyro, H.W., Ranieri, A., Abdelly, C., Smaoui, A.: Phytodesalination of a salt-affected soil with the halophyte Sesuvium portulacastrum L. to arrange in advance the requirements for the successful growth of a glycophytic crop. - Bioresour. Technol. 101: 6822-6828, 2010.

Re, R., Pellegrini, N., Proteggente, A., Pannala, A., Yang, M., Rice-Evans, C.: Antioxidant activity applying an improved ABTS radical cation decolorization assay. - Free Radicals Biol. Med. 26: 1231-1237, 1999.

Reginato, M.A., Castagna, A., Furlán, A., Castro, S., Ranieri, A., Luna, V.: Physiological responses of a halophytic shrub to salt stress by $\mathrm{Na}_{2} \mathrm{SO}_{4}$ and $\mathrm{NaCl}$ : oxidative damage and the role of polyphenols in antioxidant protection. - AoB Plants 6: plu042, 2014.

Ricachenevsky, F.K., Menguer, P.K., Sperotto, R.A.: kNACking on heaven's door: how important are NAC transcription factors for leaf senescence and $\mathrm{Fe} / \mathrm{Zn}$ remobilization to seeds? - Front. Plant Sci. 4: 226, 2013.

Robson, P.R.H., Donnison. I.S., Wang, K., Frame, B., Pegg, S.E., Thomas, A., Thomas, H.: Leaf senescence is delayed in maize expressing the Agrobacterium IPT gene under the control of a novel maize senescence-enhanced promoter. Plant. Biotechnol. J. 2: 101-112, 2004.

Saeed, N., Khan, M.R., Shabbir, M.: Antioxidant activity, total phenolic and total flavonoid contents of whole plant extracts Torilis leptophylla L. - BMC Complement. Alternative Med. 12: 221, 2012.

Sakuraba, Y., Schelbert, S., Park, S.Y., Han, S.H., Lee, B.D., 
Andrès, C.L.B., Kessler, F., Hörtensteiner, S., Paek, N.C. STAY-GREEN and chlorophyll catabolic enzymes interact at light-harvesting complex II for chlorophyll detoxification during leaf senescence in Arabidopsis. - Plant Cell 24: 507$518,2012$.

Schippers, J.H.M., Jing, H.C., Hille, J., Dijkwel, P.P.: Developmental and hormonal control of leaf senescence. In: S. Gan (ed.): Annual Review of Senescence Processes in Plants. Vol. 26. Pp. 145-170. Blackwell Publishing, Oxford 2007.

Shi, D., Wang, D.: Effects of various salt-alkaline mixed stresses on Aneurolepidium chinense (Trin.) Kitag. - Plant Soil 271: 15-26, 2005.

Soudry, E., Shimon, U., Shimon, G.: Accumulation and remobilization of amino acids during senescence of detached and attached leaves: in planta analysis of tryptophan levels by recombinant luminescent bacteria. - J. exp. Bot. 56: 695-702, 2005.

Sperotto, R.A., Ricachenevsky, F.K., Duarte, G.L., Boff, T., Lopes, K.L., Sperb, E.R., Grusak, M.A., Fett, J.P.: Identification of up-regulated genes in flag leaves during rice grain filling and characterization of OsNAC5, a new ABA-dependent transcription factor. - Planta 230: 9851002, 2009.

Stafford, H.A.: Anthocyanins and betalains: evolution of the mutually exclusive pathways. - Plant Sci. 101: 91-98, 1994.

Stintzing, F.C., Scheiber, A., Carle, R.: Evaluation of colour properties and chemical quality parameters of cactus juices. - Eur. Food Res. Technol. 216: 303-311, 2003.

Tanaka, Y., Sasaki, N., Ohmiya, A.: Biosynthesis of plant pigments: anthocyanins, betalains and carotenoids. - Plant J. 54: 733-749, 2008.

Tyler, G.: Changes in the concentrations of major, minor and rare-earth elements during leaf senescence and decomposition in a Fagus sylvatica forest. - Forest. Ecol. Manage. 206: 167-177, 2005.

Vogt, T., Ibdah, M., Schmidt, J., Wray, V., Nimtz, M., Strack, D.: Light-induced betacyanin and flavonols accumulation in bladder cells of Mesembryanthemum crystallinum. Phytochemistry 52: 583-592, 1999.

Wang, C.Q., Zhao, J.Q., Chen, M., Wang, B.S.: Identification of betacyanin and effects of environmental factors on its accumulation in halophyte Suaeda salsa L. - J. Plant Physiol. mol. Biol. 32: 195-201, 2006.

Wang, R., Liu, S., Wang, J., Dong, Q., Xu, L., Rui, Q.: Purification, characterization and identification of a senescence related serine protease in dark-induced senescent wheat leaves. - Phytochemistry 95: 118-126, 2013.

Watanabe, M., Balazadeh, S., Tohge, T., Erban, A., Giavalisco, P., Kopka, J., Mueller-Roeber, B., Fernie, A.R., Hoefgen, R.: Comprehensive dissection of spatio-temporal metabolic shifts in primary, secondary, and lipid metabolism during developmental senescence in Arabidopsis. - Plant Physiol. 162: 1290-1310, 2013.

Weng, X.Y., Xu, H.X., Jiang, D.A.: Characteristics of gas exchange, chlorophyll fluorescence and expression of key enzymes in photosynthesis during leaf senescence in rice plants. - J. integr. Plant Biol. 47: 560-566, 2005.

Wingler, A., Purdy, S., MacLean, J.A., Pourtau, N.: The role of sugars in integrating environmental signals during the regulation of leaf senescence. - J. exp. Biol. 57: 391-399, 2006.

Witkowska, I.M., Woltering, E.J.: Plant age affects woundinduced senescence in Lactuca sativa L. - J. Plant Biochem. Physiol. 2: 119, 2013.

Wu, Y.j., Yang, T.Z., Song, Y.Y., Zhang, X.Q., Xu, S.X., Xue, G., Xing, X.X.: Metabolic regulation of ammonia emission in different senescence phenotypes of Nicotiana tabacum. Biol. Plant. 60: 190-194, 2016.

Xiao, W., Sheen, J., Jang, J.C.: The role of hexokinase in plant sugar signal transduction and growth and development. Plant mol. Biol. 44: 451-461, 2000.

Yang, C., Chong, J., Li, C., Kim, C., Shi, D., Wang, D.: Osmotic adjustment and ion balance traits of an alkali resistant halophyte Kochia sieversiana during adaptation to salt and alkali conditions. - Plant Soil 294: 263-276, 2007.

Yang, J.C., Zhang, J.H., Wang, Z.Q., Zhu, Q.S., Liu, L.J.: Involvement of abscisic acid and cytokinins in the senescence and remobilization of carbon reserves in wheat subjected to water stress during grain filling. - Plant Cell Environ. 26: 1621-1631, 2003.

Yildiz-Aktas, L., Dagnon, S., Gurel, A., Gesheva, E., Edreva, A.: Drought tolerance in cotton: involvement of nonenzymatic ROS scavenging compounds. - J. Agron. Crop Sci. 195: 247-253, 2009.

Zimmermann, P., Zentgraf, U.: The correlation between oxidative stress and leaf senescence during plant development. - Cell. mol. Biol. Lett. 10: 515-534, 2005.

Zhu, J. K.: Regulation of ion homeostasis under salt stress. Curr. Opin. Plant Biol. 6: 441-445, 2003. 